\title{
Hypoglycaemia following treatment of hyperkalaemia with insulin and dextrose
}

\author{
P.S. Williams, ${ }^{1}$ A. Davenport ${ }^{2}$ and J.M. Bone ${ }^{1}$ \\ ${ }^{1}$ Renal Unit, Royal Liverpool Hospital, Liverpool L7 8XP and ${ }^{2}$ Renal Unit, St James Hospital, Leeds LSP \\ $7 T F, U K$.
}

\begin{abstract}
Summary: We describe four patients who developed symptomatic hypoglycaemia following treatment of hyperkalaemia with insulin and dextrose. Two patients had a delayed onset of hypoglycaemia, between 5 and 6 hours after treatment despite use of a 'soluble' type of insulin. A review of the literature revealed a variety of insulin and dextrose regimes but no research to assess the metabolic effects of such therapy in patients with renal failure. The possibility of significant hypoglycaemia following use of insulin and dextrose in the recommended dosages is rarely mentioned.

The cases we describe demonstrate that there is no 'correct' dose of insulin and dextrose to suit every circumstance. Regular blood glucose estimations should be performed in all patients receiving such therapy for hyperkalaemia.
\end{abstract}

\section{Introduction}

The use of intravenous insulin and dextrose in the treatment of hyperkalaemia is well established. However, the optimum dose of insulin per gram dextrose administered is not generally agreed. It has been suggested that intravenous hypertonic dextrose alone may be all that is required unless the patient is diabetic ${ }^{1}$ but dosages of $0.2 \mathrm{IU}$ insulin/gram dextrose, ${ }^{2,3} 0.2-0.4 \mathrm{IU} / \mathrm{g},{ }^{4,5} 0.5 \mathrm{IU} / \mathrm{g},{ }^{6} 0.6 \mathrm{IU} / \mathrm{g},{ }^{7}$ and up to $1.0 \mathrm{IU} / \mathrm{g}$, e.g. 50 units soluble insulin with $100 \mathrm{ml} 50 \%$ dextrose ${ }^{8.9}$ have been advised.

Recently we have seen four patients who developed symptomatic hypoglycaemia following treatment of hyperkalaemia with insulin and dextrose. None had received any other hypoglycaemic agent, they were not diabetic and there was no evidence of hepatic failure.

\section{Case reports}

\section{Case 1}

A 69 year old female developed acute renal failure following myocardial infarction. Subsequently, she developed ventricular fibrillation and cardiac standstill, when her plasma potassium was $6.9 \mathrm{mmol} / 1$,

Correspondence: P.S. Williams, M.B., M.R.C.P.

Accepted: 6 July 1987 plasma urea $32 \mathrm{mmol} / 1$. Resuscitation was successfuf in re-establishing cardiac output. Immediate therapy had included $50 \mathrm{ml} 50 \%$ dextrose and 14 IU actrapid insulin intravenously $(0.56 \mathrm{IU}$ insulin/g dextrose). Two and a half hours after the cardiac arrest she remained unrousable. Venous blood glucose, at this time, was $1.6 \mathrm{mmol} / 1(28 \mathrm{mg} / \mathrm{dl})$. Following administration of $50 \mathrm{ml} 50 \%$ dextrose and maintenance of blood glucose concentration at greater than $5 \mathrm{mmol} / \mathrm{l}$ with a dextrose infusion there was a gradual improvement in the patient's level of consciousness. Twenty-four hours after the cardiac arrest she was conscious and fully brientated.

\section{Case 2}

A 23 year old man with a well functioning renal allograft was admitted for minor surgery under general anaesthesia. His drug therapy included cyclosporin A $350 \mathrm{mg} /$ day and labetalol $800 \mathrm{mg} /$ day. On the morning of surgery, plasma potassium was $6.5 \mathrm{mmol} / 1$, plasma urea $11.3 \mathrm{mmol} / \mathrm{l}$. Fifty $\mathrm{ml} 50 \%$ dextrose and $10 \mathrm{IU}$ actrapid insulin $(0.4 \mathrm{IU} / \mathrm{g})$ were administered intravenously for control of hyperkalaemia. A $5 \%$ dextrose infusion running at $125 \mathrm{ml}$ per hour was also commenced. Two hours later, just prior to his transfer for surgery, he became pale, sweaty and barely rousable. Blood glucose estimation on 'dextrostix' (Ames Laboratories) was less than $2.5 \mathrm{mmol} / 1(45 \mathrm{mg} / \mathrm{dl})$.

(C) The Fellowship of Postgraduate Medicine, 1988 
One hundred $\mathrm{ml} 50 \%$ dextrose were given intravenously with prompt resolution of his symptoms.

\section{Case 3}

A 32 year old female was admitted to another hospital with acute pulmonary oedema. She was found to be in renal failure: plasma urea $80.1 \mathrm{mmol} / 1$, plasma potassium $6.9 \mathrm{mmol} / 1$. Initial therapy included $20 \mathrm{ml} 50 \%$ dextrose with $20 \mathrm{IU}$ actrapid insulin (i.e. 2 units insulin/g dextrose). She was subsequently transferred to our unit where she was treated by haemodialysis and ultrafiltration (glucose concentration of dialysate $10 \mathrm{mmol} / \mathrm{l}$ ). Five hours after admission, whilst still on haemodialysis, her level of consciousness deteriorated abruptly. On examination, there was no response to painful stimuli. Her pupils were dilated but reacted to light. Muscular tone was increased and she was hyperreflexic. Plantar responses were downgoing bilaterally. One hundred $\mathrm{ml} 50 \%$ dextrose were administered intravenously with prompt resolution of all the abnormal neurological signs. There was no detectable glucose on laboratory analysis (YSI Glucose Analyser) of a venous blood sample taken just prior to the administration of dextrose.

\section{Case 4}

A 32 year old man who had been on haemodialysis for 12 years was admitted with a thrombosed arterio-venous (AV) fistula. Thrombectomy was performed under local anaesthetic on the day of admission. A subclavian dialysis cannula was inserted via which haemodialysis was performed the following day. Two days later a further exploration of the AV fistula was carried out. However, prior to surgery the plasma potassium was $7.3 \mathrm{mmol} / 1$. Fifty $\mathrm{ml} 50 \%$ dextrose and $10 \mathrm{IU}$ actrapid insulin $(0.4 \mathrm{IU} / \mathrm{g})$ were therefore administered intravenously. Post-operatively, and some 6 hours after receiving insulin and dextrose the patient was commenced on haemodialysis. After 30 minutes dialysis he suffered a cardiac arrest at which time blood glucose was found to be $1.1 \mathrm{mmol} / \mathrm{l}$ and potassium $4.5 \mathrm{mmol} / \mathrm{l}$. The cardiac arrest was considered to be multifactorial in origin with metabolic abnormalities, including hypoglycaemia, playing a prominent role. The patient was resuscitated and given one hundred $\mathrm{ml} 50 \%$ dextrose which corrected the hypoglycaemia. However, he remained unconscious and required

\section{References}

1. Levinsky, N.E. In: Harrson's Principles and Practice of Medicine, 10th edition. McGraw Hill, 1983, pp 228-229. ventilation for 72 hours before eventually making a full recovery.

\section{Discussion}

It has been known for many years that insulin causes a shift of potassium from extracellular to intracellular fluids thereby reducing the concentration in plasma. Hypertonic glucose alone given intravenously can produce a fall in plasma potassium in normal subjects due to the action of endogenous insulin. ${ }^{10}$ However, most clinicians add small doses of insulin to the intravenous glucose infusion in order to accelerate and accentuate the potassium lowering effect. We are not aware of any research in humans which has compared varying dosages of insulin and dextrose in the treatment of hyperkalaemia. The cases we describe demonstrate that there is no 'correct' dose of insulin per gram dextrose to suit every circumstance. Our third patient received an inappropriately high dose of insulin per gram dextrose but the three others developed hypoglycaemia when dosages within the advised range were given $(0.56,0.4$ and $0.4 \mathrm{IU}$ insulin/g dextrose respectively). The response to insulin will depend upon many factors including the patient's age, general level of nutrition, any period of starvation, e.g. prior to surgery, and concurrent use of non-selective beta blockers which may slow recovery from hypoglycaemia through inhibition of the glycogenolytic and lipolytic action of endogenous catecholamines. Moreover, in patients with renal failure the metabolism of insulin is impaired and the onset of hypoglycaemia may be delayed; ${ }^{11}$ note that in cases 3 and 4 symptomatic hypoglycaemia did not occur until five and six hours after receiving insulin and dextrose. Uraemic factors, too, may retard the recovery of blood glucose concentration after an episode of insulin induced hypoglycaemia, possibly through decreased availability of hepatic glycogen. ${ }^{12}$

If insulin is used with hypertonic glucose to treat hyperkalaemia then its dosage (IU/g) must be adjusted to take account of these factors. A fixed dose of insulin per gram dextrose is not suitable for all circumstances. Also, more importantly, blood glucose concentrations should be monitored regularly for several hours after the administration of insulin. This simple advice is not usually found in most popular textbooks and the possibility of hypoglycaemia occurring following use of insulin and dextrose in the dosages they recommend is rarely mentioned.

2. Hamburger, J., Crosnier, J., \& Grunfeld, J. Nephrology. J. Wiley and Sons, Chichester, 1979, p 295. 
3. Davidson's Principle and Practice of Medicine, 14th edition. Churchill Livingstone, Edinburgh, London, 1984, p 94.

4. Oxford Textbook of Medicine, Ch 18. Oxford Medical Publications, Oxford, 1983. p 115.

5. Rubinstein, D. and Wayne, D. Lecture Notes on Clinical Medicine, 2nd edition. Blackwell Scientific Publications, Oxford, 1980, p 195.

6. Houston, J.C., Joiner, C.L. \& Trounce, J.R. Short Textbook of Medicine, 7th edition. Unibooks. 1982. 507.

7. Hopton, D.S. Practical Hints for Housemen, 2nd edition. Lloyd-Luke, London, 1980, p 118.

8. Jones, E.S. Essential Intensive Care, MTP Press, Lancaster, 1981, p 147.
9. Coward, R.A., Short, C.D. \& Mallick, N.P. Case Presentations in Renal Medicine. Butterworths, London, 1983, p 12.

10. Groen, J., Willebrands, A.F., Kamming, C.E. et al. Effects of glucose administration on the potassium, inorganic phosphate content of the blood serum and electrocardiograms in normal individuals and nondiabetic patients. Acta Med Scand 1952, 141: 352366.

11. Westervelt, G.F. \& Schreiner, G. Carbohydrate intolerance of uraemic patients. Ann Intern Med 1962, 57: 266-275.

12. Cohen, B.D. Abnormal carbohydrate metabolism in renal disease. Ann Intern Med 1962, 57: 205-213. 